Article

\title{
Antioxidant Activity of a Novel Acetylcholinesterase Inhibitor: In Vivo and Ex vivo Studies
}

\author{
Rumiana Simeonova ${ }^{1}$, Georgi Stavrakov 1,2 , Irena Philipova ${ }^{2}$, Mariyana Atanasova ${ }^{1}$ and Irini Doytchinova 1,* \\ 1 Faculty of Pharmacy, Medical University of Sofia, 1000 Sofia, Bulgaria; rsimeonova@pharmfac.mu-sofia.bg; \\ gstavrakov@pharmfac.mu-sofia.bg; matanasova@pharmfac.mu-sofia.bg \\ 2 Institute of Organic Chemistry with Centre of Phytochemistry, Bulgarian Academy of Sciences, 1113 Sofia, \\ Bulgaria; irena@orgchm.bas.bg \\ * Correspondence: idoytchinova@pharmfac.mu-sofia.bg
}

\begin{abstract}
The acetylcholinesterase (AChE) inhibitors are the main drugs for symptomatic treatment of neurodegenerative disorders like Alzheimer's disease. A recently designed, synthesized and tested hybrid compound between the AChE inhibitor galantamine (GAL) and the antioxidant polyphenol curcumin (CU) showed high AChE inhibition in vitro. Here, we describe tests for acute and short-term toxicity in mice as well as antioxidant tests on brain homogenates measured the levels of malondialdehide (MDA) and glutathione (GSH). Haematological and serum biochemical analyses were also performed. In the acute toxicity tests, the novel AChE inhibitor given orally in mice showed LD50 of $49 \mathrm{mg} / \mathrm{kg}$. The short-term administration of 2.5 and $5 \mathrm{mg} / \mathrm{kg}$ did not show toxicity. In the ex vivo tests, the GAL-CU hybrid performed better than GAL and CU themselves. In a dose of $5 \mathrm{mg} / \mathrm{kg}$, it demonstrates $25 \%$ reduction in AChE activity, $28 \%$ and $73 \%$ increase in the levels of MDA and GSH, respectively. No significant changes in blood biochemical data were observed. The GAL-CU hybrid is a novel non-toxic AChE inhibitor with high antioxidant activity which makes it a perspective multitarget drug candidate for treatment of Alzheimer's disease.
\end{abstract}

Keywords: galantamine; curcumin; in vivo AChE inhibition; acute toxicity in mice; antioxidant activity; malondialdehide levels; glutathione levels; brain homogenate; complete blood count; biochemical serum parameters

\section{Introduction}

The neurodegenerative disorders like Alzheimer's and Parkinson diseases rise exponentially every ten years and during the next few decades will overtake cancer and become the second leading cause of death after cardiovascular diseases [1]. The successful treatment of these disorders requires reliable tests and biomarkers for early diagnosis, identification of translational drug targets and fast discovery and development of multitarget drugs and therapeutic strategies to tackle the complex pathogenesis of the neurodegeneration.

In the last 20 years, the main drugs used to cope with some of the symptoms of Alzheimer's disease (AD) are inhibitors of the enzyme acetylcholinesterase (AChE). The reversible AChE blockage increases the levels of acetylcholine (ACh) - the main neurotransmitter associated with the cognitive and motor brain functions. Galantamine (GAL) (Figure 1) is among the few AChE inhibitors approved for treatment of AD [2]. Additionally, GAL is an allosteric modulator of nicotinic and muscarinic ACh receptors [3,4], increases the phagocytosis of amyloid $\beta(\mathrm{A} \beta)$ peptide in rat microglia [5], exhibits a moderate scavenging effect in antioxidant studies [6].

The oxidative stress hypothesis in $\mathrm{AD}$ dates back to the late 1990s [7,8]. According to this hypothesis, the mammals' brain is very sensitive to oxidative stress because of the abundant presence of polyunsaturated fatty acids and transition metals like iron, copper 
and zinc [9] and the relative shortage of antioxidant ability to detoxify the free radicals [10]. Most of the clinical trials report associations between antioxidant use and better cognitive functions [11-15]. Curcumin (CU) (Figure 1) is a natural polyphenol with a powerful antioxidant activity [16] and ability to reduce oxidative stress and amyloid pathology in transgenic mice [17]. Additionally, it was found that CU binds to A $\beta$ oligomers and fibrils and inhibits the $\beta$-sheet formation [18]. We simulated the primary nucleation of $\mathrm{A} \beta$ peptide by molecular dynamics and showed that $\mathrm{CU}$ molecules inhibit the process by intercalating among the A $\beta$ chains [19]. Even more, CU is able to disintegrate preformed $A \beta$ fibrils [18], reduce insoluble $A \beta$ deposits [20] and amyloid plaques [21].

Recently, we designed a combinatorial library of GAL-CU hybrids, screened for optimal ADME properties and blood-brain permeability and docked on AChE [19]. The 14 best performing hybrids were synthesized and tested for neurotoxicity and AChE inhibition in vitro. Five of them showed less toxicity than GAL and CU and AChE inhibition between 41 and 186 times higher than GAL. Here, we describe the in vivo evaluation of acute and short-term toxicity and the ex vivo antioxidant properties of the best performing inhibitor - compound $\mathbf{4 b}$. As the present study is a continuation of our previous research [19] and will be followed by other studies on this particular compound, we prefer to keep the same compound ID. As positive controls in the study are used GAL and CU.<smiles>CC[C@@]12C=C[C@H](O)C[C@@H]1Oc1c(OC)ccc(CN(C)C)c12</smiles><smiles>COc1cc(/C=C/C(=O)CC(=O)/C=C/c2ccc(O)c(OC)c2)ccc1O</smiles>

CU<smiles></smiles>

$4 b$

Figure 1. Structures of Galantamine (GAL), Curcumin (CU) and their hybrid $\mathbf{4 b}$.

\section{Materials and Methods}

\subsection{Materials}

In the present study were used the following materials: galantamine $\mathrm{HBr}$ (Galen-N Ltd., Sofia, Bulgaria, $\mathrm{Mw}=368.3 \mathrm{~g} / \mathrm{mol}$, purity $>98 \%$ ), curcumin (BioXtract, Belgium, Mw $=368.4 \mathrm{~g} / \mathrm{mol}$, purity $>98 \%$ ), bovine serum albumin (Sigma Aldrich, Germany, Mw $\approx 66$ kD, purity $>96 \%$ ), thiobarbituric acid (Sigma Aldrich, Germany, Mw $=144.15 \mathrm{~g} / \mathrm{mol}$, purity $>98 \%$ ), trichloroacetic acid (Sigma Aldrich, Germany, Mw = $163.39 \mathrm{~g} / \mathrm{mol}$, purity > 99\%), acetylthiocholineiodide (Sigma Aldrich, Germany, $\mathrm{Mw}=289.18$, purity $>98 \%$ ), 2,2Dinitro-5,5 dithiodibenzoic acid (DTNB) (Sigma Aldrich, Germany, Mw =396.35, purity > 98\%), Ethylenediaminetetraacetic acid (EDTA) (Sigma Aldrich, Germany, Mw = 292.24, purity $>99 \%$ ). 
The synthesis of $\mathbf{4 b}$ and detailed analytical data is already reported in the context of the synthesis of a series of GAL-CU hybrids [19]. A contribution of the herein reported synthetic procedures is upscale and optimization of the protocols.
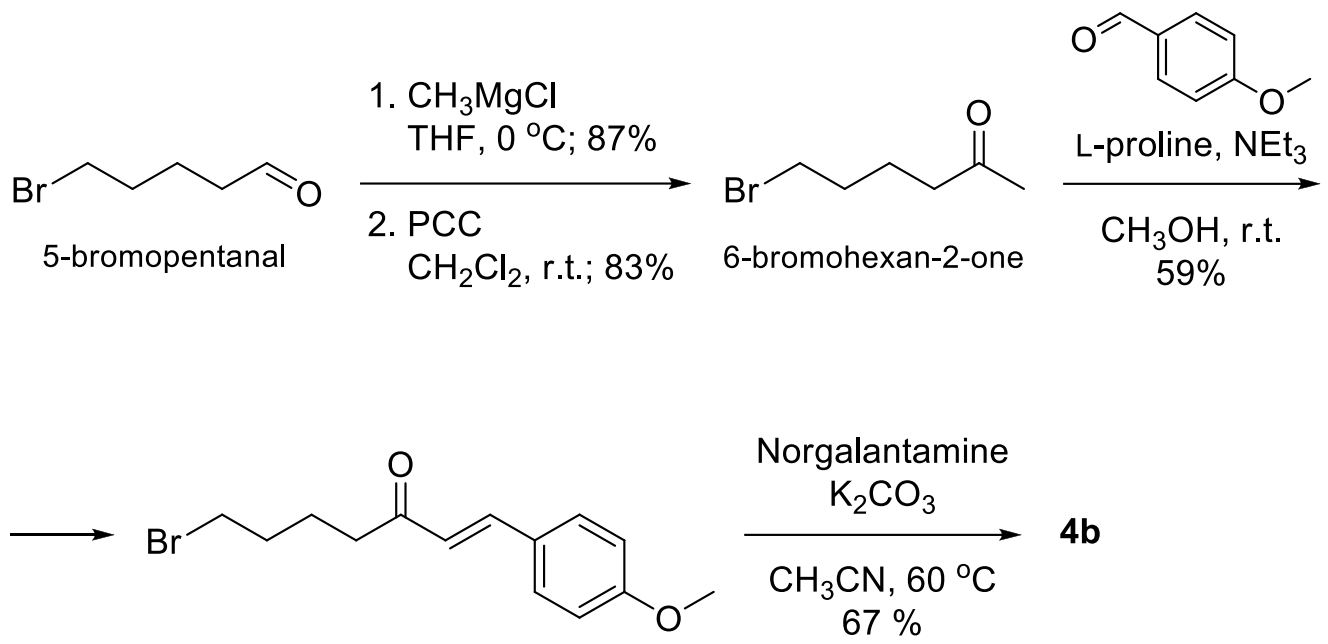

(E)-7-bromo-1-(4-methoxyphenyl)hept-1-en-3-one

Scheme 1. Synthesis of $4 \mathbf{b}$.

A stirred solution of 5-bromopentanal $(1.038 \mathrm{~g}, 6.29 \mathrm{mmol})$ in dry THF (25 ml) under argon atmosphere was treated dropwise at $0 \mathrm{oC}$ with $\mathrm{CH} 3 \mathrm{MgCl}(3 \mathrm{M}$ in THF, $4.2 \mathrm{ml}, 12.58$ $\mathrm{mmol})$. The reaction was stirred for $30 \mathrm{~min}$ at r.t., cooled down to $0 \mathrm{oC}$ and quenched with $10 \mathrm{ml}$ sat.aq. $\mathrm{NH} 4 \mathrm{Cl}$. The resulting mixture was extracted (ether), dried (MgSO4), filtered, concentrated and purified by flash column chromatography to give 6-bromohexan-2-ol in 87\% yield. A suspension of 6-bromohexan-2-ol (0.782 g, 4.32 $\mathrm{mmol})$, PCC (1.862 g, $8.64 \mathrm{mmol})$ and Celite $(0.500 \mathrm{~g})$ in $\mathrm{CH} 2 \mathrm{Cl} 2(25 \mathrm{ml})$ was stirred for 18 $\mathrm{h}$ at r.t. The mixture was diluted with petroleum ether $(75 \mathrm{ml})$, filtered through a pad of Celite, concentrated and subjected to flash column chromatography to give 6-bromohexan-2-one in $83 \%$ yield.

A solution of 6-bromohexan-2-one $(0.615 \mathrm{~g}, 3.435 \mathrm{mmol}), \mathrm{p}$-methoxybenzaldehyde (0.562 g, $4.122 \mathrm{mmol})$, L-proline $(0.06 \mathrm{~g}, 0.515 \mathrm{mmol})$ and NEt3 (0.104 g, $1.031 \mathrm{mmol})$ in methanol $(7 \mathrm{ml})$ was stirred at r.t. for 5 days. The mixture was concentrated and directly subjected to flash column chromatography to give (E)-7-bromo-1-(4-methoxyphenyl)hept -1-en-3-one in 59\% yield. The latter bromide $(0.248 \mathrm{~g}, 0.834 \mathrm{mmol})$ and anhydrous K2CO3 $(0.314 \mathrm{~g}, 2.276 \mathrm{mmol})$ were added to a solution of Norgalantamine $(0.207 \mathrm{~g}, 0.759 \mathrm{mmol})$ in anhydrous acetonitrile $(20 \mathrm{~mL})$ under argon atmosphere. After stirring for $24 \mathrm{~h}$ at 60 oC, the mixture was filtered through a pad of Celite, concentrated and purified by flash column chromatography to give $0.249 \mathrm{~g}(67 \%)$ the desired product $4 \mathrm{~b}$.

\subsection{Animals}

Male and female ICR mice (6 weeks old, 25-35 g) obtained from the National Breeding Center, Sofia, Bulgaria were used in the experiments. As a more sensitive sex [22], 18 females were used in the acute toxicity test and 30 males in the short-term toxicity test. Mice were housed in Plexiglas cages (6 per cage) in a 12/12 light/dark cycle, under standard laboratory conditions (ambient temperature $20^{\circ} \mathrm{C} \pm 2{ }^{\circ} \mathrm{C}$ and humidity $72 \% \pm$ $4 \%$ ) with free access to water and standard pelleted food № 53-3, produced in accordance with ISO9001:2008. Prior to the start of the experiment, the mice were acclimatized under vivarium conditions for seven days and their health was monitored daily by a veterinarian. The vivarium (registration certificate № 15320139/01.08.2007) was inspected by the Executive Agency for Medicines in order to verify the conditions for keeping laboratory animals (№ A-16-0532/14.10.2016). All experiments strictly followed the principles 
set out in the European Convention for the Protection of Vertebrate Animals Used for Experimental and Other Scientific Purposes (ETS 123) (Council of Europe, 1991). Efforts have been made to minimize animal suffering. The Animal Care Ethic Committee approved the study protocol and Ethic clearance (№ 273 from 02/06/2020) was issued for the study by the Bulgarian Agency for Food Safety.

\subsection{Acute Toxicity Protocol}

Acute toxicity test was performed on female mice after oral (po) administration of 4b using a simplified Lorke's method [23]. Three animals per dose were used, starting with a dose of $10 \mathrm{mg} / \mathrm{kg}$ and gradually increasing it every $3 \mathrm{~h}$ until the first lethal case. Compound $4 \mathrm{~b}$ was solubilized with Tween $80(0.1 \%)$ in distilled water and administered orally in a volume of $0.1 \mathrm{ml} / 10 \mathrm{~g}$.

The LD50 is calculated using the following equation:

$L D_{50}=\sqrt{\left(D_{0} \times D_{100}\right)}$,

where $\mathrm{D}_{0}$ is the highest dose that does not cause mortality and $\mathrm{D}_{100}$ is the lowest dose that results in death.

Surviving animals were observed for 24 hours and then for up to 14 days. On day 14 , they were euthanized after anesthesia with ketamine/xylazine $(80 / 10 \mathrm{mg} / \mathrm{kg}$, i.p.) and an examination of the internal organs for possible macroscopic abnormalities (organ color, consistency, neoplasms, etc.) was made.

\subsection{Short-Term Toxicity Protocol}

The short-term toxicity test was performed on male ICR mice at the same age of 6 weeks and approximately 30-35 g. Three drugs (GAL, CU and $\mathbf{4 b}$ ) were administered daily for 14 days orally with a dosing needle at approximately the same time of day, 11.00 h. Based on the $\mathrm{LD}_{50}$ value $\approx 50 \mathrm{mg} / \mathrm{kg}$, derived in the acute toxicity test, two doses of 2.5 $\mathrm{mg} / \mathrm{kg}$ and $5 \mathrm{mg} / \mathrm{kg}$ (1/20 and 1/10 of the LD50) were selected for multiple administration of $\mathbf{4 b}$. The animals were divided into 5 experimental groups of 6 mice $(n=6)$. Group 1 was the control group treated with physiological saline via oral gavage $(0.1 \mathrm{ml} / 10 \mathrm{~g} \mathrm{bw})$; group 2 was treated orally with the positive control GAL in dose of $3 \mathrm{mg} / \mathrm{kg}$ dissolved in distilled water [24]; group 3 was treated orally with the second positive control CU at a dose of $25 \mathrm{mg} / \mathrm{kg}$ [25]; group 4 was treated orally with $4 \mathbf{b}$ at a dose of $2.5 \mathrm{mg} / \mathrm{kg}(1 / 20$ LD50); group 5 was treated orally with $4 \mathbf{b}$ at a dose of $5 \mathrm{mg} / \mathrm{kg}$ (1/10 LD50).

Animals were observed daily for behavioral changes and signs of toxicity.

On day 15, after 14-day treatment, the animals were anesthetized with ketamine/xylazine $(80 \mathrm{mg} / 10 \mathrm{~kg}$ ip) and decapitated. Blood was taken in vacutainers for complete blood count and biochemistry measurment. The brains were dissected, measured and prepared for the assessment of AChE inhibition, MDA and GSH levels. Protein content of brain homogenates was measured by the method of Lowry [26] using bovine serum albumin as a standard.

\subsection{Measurement of Acetylcholinesterase (AChE) Inhibition in Brain Homogenate}

Brains were homogenized with $0.1 \mathrm{M}$, phosphate buffer, pH 7.4. Aliquots of brain homogenates from different groups were used to measure AChE activity for $10 \mathrm{~min}$ by the method of Ellman [27]. AChE activity was calculated and expressed as nmol/min/mg protein using a molar absorption coefficient of $13,600 \mathrm{M}^{-1} \mathrm{~cm}^{-1}$.

\subsection{Measurement of Malondialdehyde (MDA) Levels in Brain Homogenate}

Brains were homogenized with $0.1 \mathrm{M}$ phosphate buffer and EDTA, pH 7.4. Aliquots of the homogenates were heated for 20 minutes on a water bath $\left(100^{\circ} \mathrm{C}\right)$ with thiobarbituric acid. The amount of thiobarbituric acid-formed reactive species (TBARS) (expressed as MDA equivalents) was measured spectrophotometrically by the method of Deby and Goutier [28] at a wavelength of $535 \mathrm{~nm}$. The concentration of MDA was calculated using a molar absorption coefficient of $1,56 \times 10^{5} \mathrm{M}^{-1} \mathrm{~cm}^{-1}$ and expressed in $\mathrm{nmol} / \mathrm{g}$ tissue. 


\subsection{Measurement of Glutathione (GSH) Levels in Brain Homogenate}

GSH was evaluated by measuring non-protein sulfhydryls after trichloroacetic acid (TCA) protein precipitation by the method described by Bump et al. [29]. Brains were homogenized in $5 \%$ TCA (1:10) and centrifuged for $20 \mathrm{~min}$ at $4000 \times \mathrm{g}$. The reaction mixture contained $0.05 \mathrm{~mL}$ supernatant, $3 \mathrm{~mL} 0.05 \mathrm{M}$ phosphate buffer $(\mathrm{pH}=8)$, and $0.02 \mathrm{~mL}$ DTNB reagent. Absorption was determined at a wavelength of $412 \mathrm{~nm}$ and the results were expressed as $\mathrm{nmol} / \mathrm{g}$ tissue.

\subsection{Measurement of Haematological and Serum Biochemical Data}

Whole blood was analyzed by a semi-automated hematological analyzer BC-2800 Vet, (Mindray, China) according to the manufacturer's instructions. The count of leukocytes (WBC), erythrocytes (RBC, Er), platelets (PLT), amount of hemoglobin (Hb), hematocrit $(\mathrm{Ht})$, as well as the differential count of leukocytes were measured. The biochemical serum data as blood sugar (GLU), cholesterol (CHOL), triglycerides (TRIG), urea (UREA), creatinine (CREAT), total protein (TP), albumin (ALB), total bilirubin -Bil), direct bilirubin (D-Bil), calcium (Ca), uric acid (Uric acid), as well as the activity of the enzymes aspartate aminotransferase (ASAT), alanine aminotransferase (ALAT), alkaline phosphatase (ALP), gamma glutamyl transferase (GGT) and amylase (AMYL) were measured using automated biochemistry analyzer kits (BS-120, Mindray, China), following the manufacturer's instructions.

\subsection{Statistical Analysis}

The MEDCALC statistical program was used to analyze the in vivo data. Results are expressed as mean \pm SD for six animals in each group. The significance of the data was assessed by a nonparametric Mann-Whitney $U$ test. Values of $p \leq 0.05$ are considered as statistically significant.

\section{Results}

\subsection{Acute Toxicity in Mice}

The median lethal dose (LD50) of $\mathbf{4 b}$ in mice was $49 \mathrm{mg} / \mathrm{kg}$. No serious toxic effects or mortality were observed in mice at doses of 10 and $20 \mathrm{mg} / \mathrm{kg}$. At dose of $40 \mathrm{mg} / \mathrm{kg}$, tachypnea and mild tremor for up to 2 hours were observed with no other visible signs of toxicity. At dose of $60 \mathrm{mg} / \mathrm{kg}$, one fatal outcome was observed $3 \mathrm{~h}$ post-dosing with accelerated breathing, piloerction, mild tremor and seizures. Forthteen days later, the animals were euthanized and a macroscopic examination of the internal organs was performed. No changes in the size, color and consistency of the lungs, liver, heart, kidneys, stomach, spleen, and intestines were observed. No abnormalities in the morphology of the gonads and brain were detected.

\subsection{Short-term Toxicity in Mice}

The short-term toxicity of $4 \mathrm{~b}$ was assessed by daily administration of $2.5 \mathrm{mg} / \mathrm{kg}(1 / 20$ of $\left.\mathrm{LD}_{50}\right)$ and $5 \mathrm{mg} / \mathrm{kg}\left(1 / 10\right.$ of $\left.\mathrm{LD}_{50}\right)$ for 14 days, according to the protocol described in Materials and Methods. As positive contols were used GAL in dose of $3 \mathrm{mg} / \mathrm{kg}(1 / 10$ of LD 50 ) and CU in dose of $25 \mathrm{mg} / \mathrm{kg}$ (1/10 of LD50). A control (placebo) group also was included in the test. Animals were examined daily and no behavioral changes and signs of toxicity were observed. On day 15, the animals were anesthetized and decapitated. Blood from each group was collected for haematological and serum biochemical analuses. Brains from each group were collected as described in Material and Methods and prepared for measurements of AChE inhibition, MDA and GSH levels.

\subsection{AChE Inhibition in Mice Brain Homogenate}

After 14-day treatment of mice by GAL, CU, $\mathbf{4 b}$ or placedo, the AChE activity was measured for 10 min by the Ellman's method as described in Materials and Methods. The 
results are given in Figure 2. CU caused a mild decrease in AChE activity, followed by GAL and $\mathbf{4 b}$. The AChE decrease of $\mathbf{4 b}$ is dose-dependent. The dose of $5 \mathrm{mg} / \mathrm{kg}$ causes $25 \%$ inhibition of enzyme activity compared to the control group.

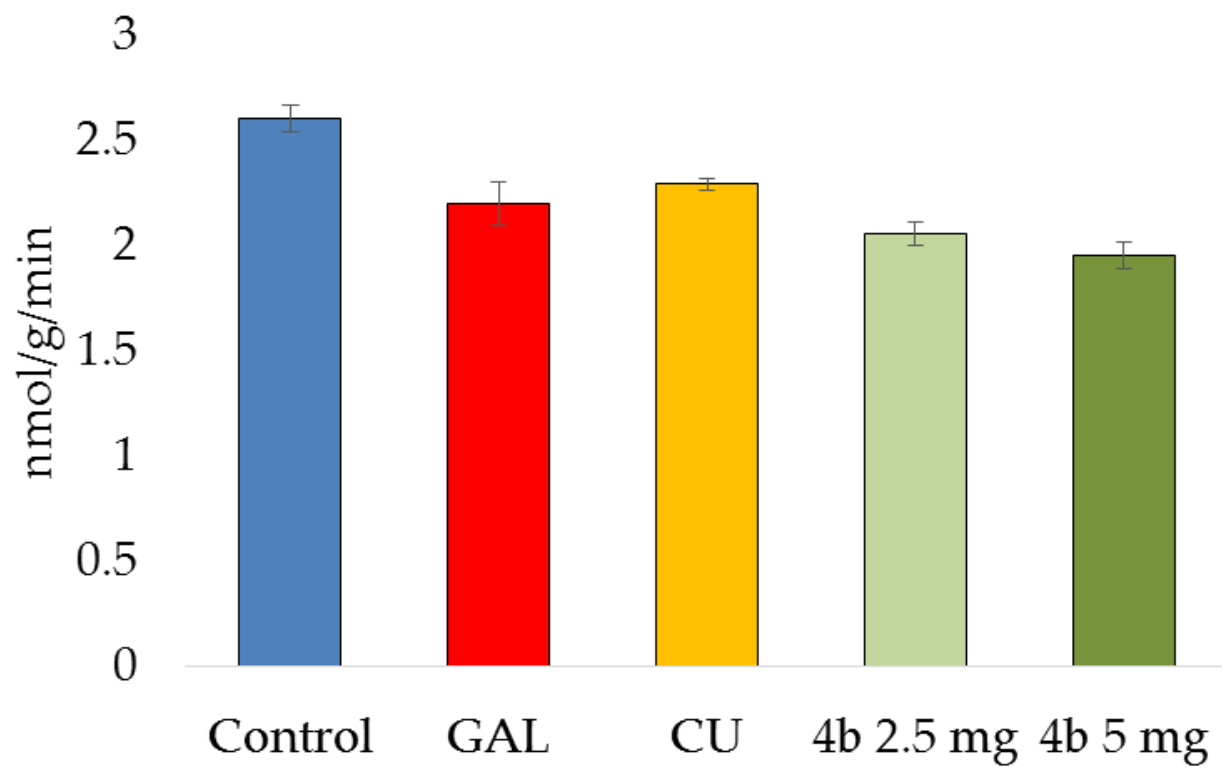

Figure 2. AChE activity measured for $10 \mathrm{~min}$ in brain homogenates derived from mice treated 14 days by GAL, CU, $4 \mathbf{b}$ in two doses $(2.5 \mathrm{mg} / \mathrm{kg}$ and $5 \mathrm{mg} / \mathrm{kg}$ ) or placebo (control group). $\mathrm{p}<0.05$ vs. control.

\subsection{Antioxidant Activity in Mice Brain Homogenate}

The antioxidant activity of the tested compounds after 14-day treatment, was assessed by measuring the levels of malondialdehyde (MDA) and gluthathione (GSH) in mice brain homogenates as described in Materials and Methods. MDA is a specific marker for lipid peroxidation. The thiobarbituric acid (TBA) test is widely used to measure the formation of red pigment, which is an adduct of TBA with aldehydes, MDA, ketones and others. The effects of the tested compounds on MDA levels are given in Figure 3a. All compounds caused increase of MDA levels: CU - by $9 \%$, GAL - by $26 \%, 4 b$ in dose $2.5 \mathrm{mg} / \mathrm{kg}$ - by $24 \%$ and $4 \mathrm{~b}$ in dose $5 \mathrm{mg} / \mathrm{kg}$ - by $28 \%$ compared to control. The effect of $\mathbf{4 b}$ on MDA levels is dose-dependent.

The oxidative stress causes decrease in GSH levels [9]. All tested compounds in the present study elevated the GSH levels (Figure 3b) showing antioxidant activity. The most prominent effect has $\mathbf{4 b}$ in dose of $5 \mathrm{mg} / \mathrm{kg}(73 \%)$, followed by $4 \mathrm{~b}$ in dose of $2.5 \mathrm{mg} / \mathrm{kg}$ $(67 \%), \mathrm{CU}(52 \%)$ and GAL $(35 \%)$. Here again, the effects of $4 \mathbf{b}$ on GSH levels is dose-dependent. 


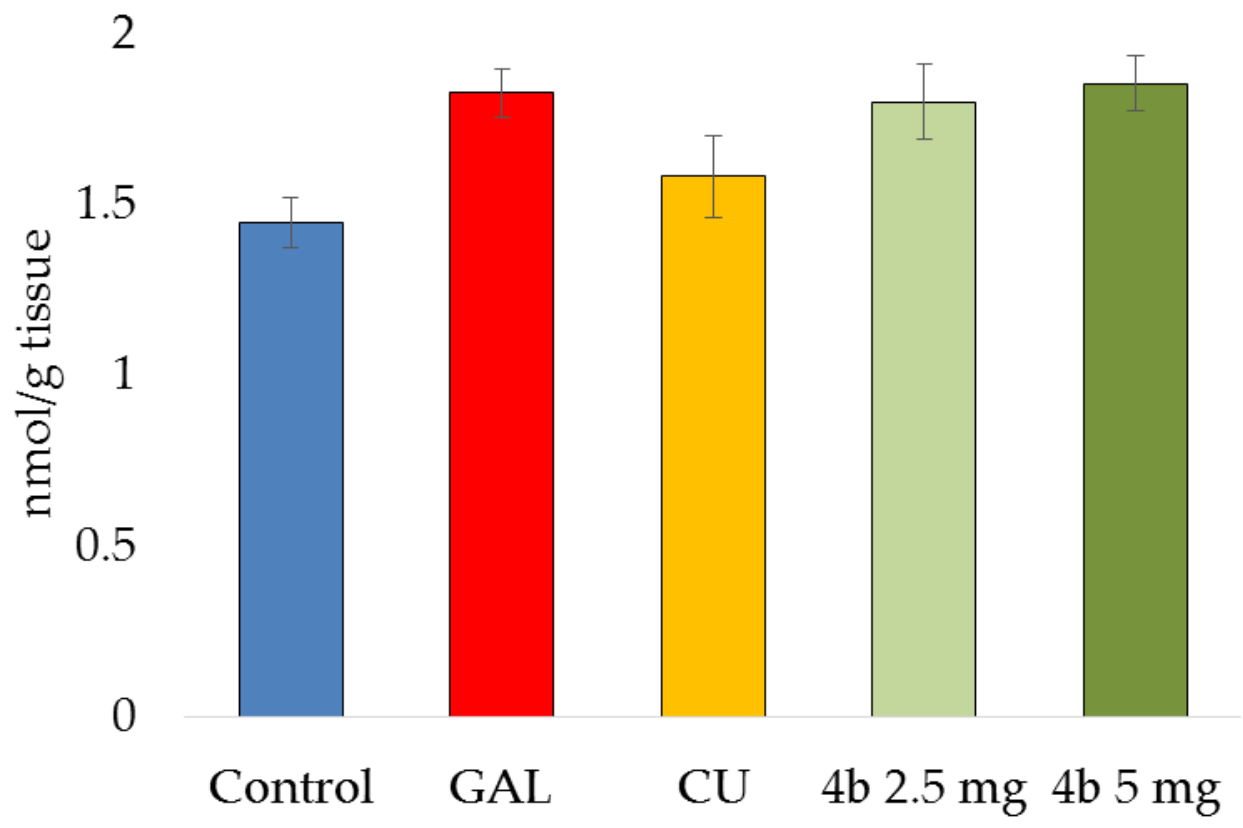

(a)

\section{5}

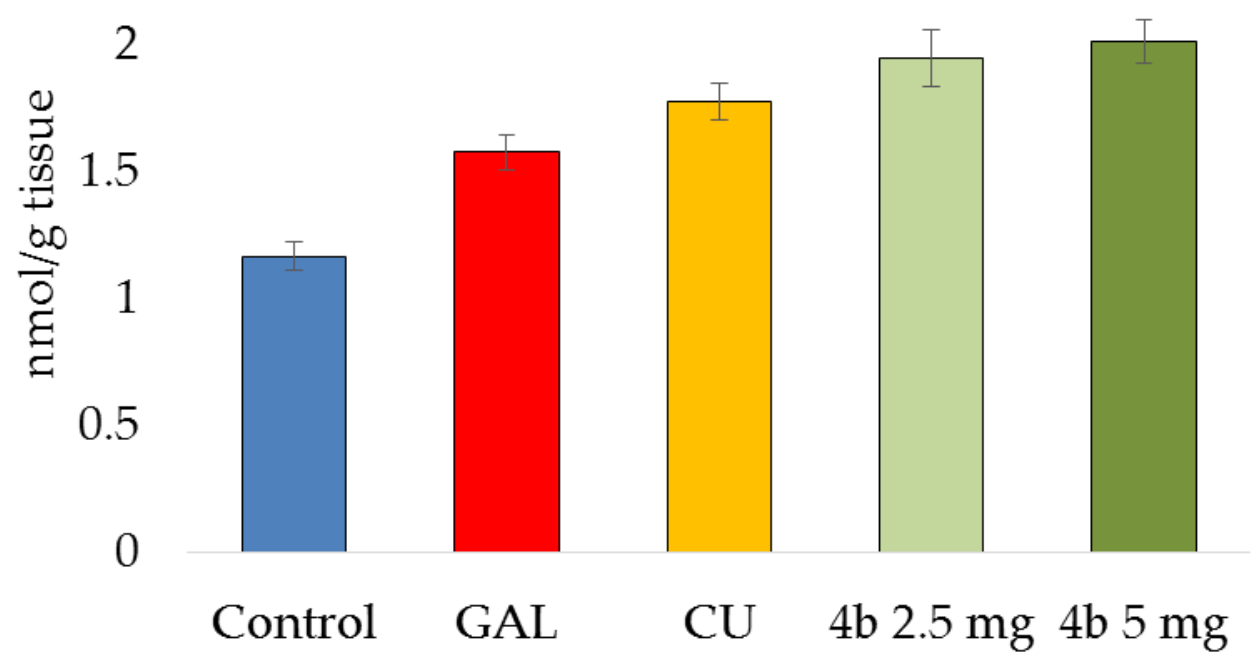

(b)

Figure 3. Antioxidant activity measured by MDA (a) and GSH levels (b) in brain homogenates derived from mice treated 14 days by GAL, CU, $4 \mathbf{b}$ in two doses $(2.5 \mathrm{mg} / \mathrm{kg}$ and $5 \mathrm{mg} / \mathrm{kg})$ or placebo (control group). $\mathrm{p}<0.05$ vs. control.

\subsection{Haematological and Serum Biochemical Data}

The haematological data after 14-day treatment by GAL, CU, two doses of $\mathbf{4 b}$ or placebo are summarized in Table 1 . There are no statistically significant deviations from the reference values for mice (embedded in the analyzer's software), indicating no adverse effect of the test substances on hematopoiesis. 
Table 1. Haematological data after 14-day treatment by GAL, CU, two doses of $\mathbf{4 b}$ or placebo. Values are means \pm standard deviation $(n=6)$. Mice reference ranges are given according to analyzer's software.

\begin{tabular}{|c|c|c|c|c|c|c|}
\hline $\begin{array}{c}\text { Complete } \\
\text { Blood Count }\end{array}$ & Control & GAL & CU & $\begin{array}{c}4 \mathrm{~b} \\
2.5 \mathrm{mg} / \mathrm{kg}\end{array}$ & $\begin{array}{c}4 \mathrm{~b} \\
5 \mathrm{mg} / \mathrm{kg}\end{array}$ & $\begin{array}{c}\text { Mice Ref- } \\
\text { erence } \\
\text { Range }\end{array}$ \\
\hline $\mathrm{WBC} \times 10^{9} / \mathrm{L}$ & $4,8 \pm 0,62$ & $3,9 \pm 0,43$ & $2,9 \pm 0,22$ & $5,4 \pm 0,37$ & $4,1 \pm 0,2$ & $2,9-15,3$ \\
\hline LYM x 109/L & $3,4 \pm 0,56$ & $2,6 \pm 0,72$ & $2,6 \pm 0,66$ & $3,9 \pm 0,5$ & $3,0 \pm 0,7$ & $2,6-13,5$ \\
\hline $\mathrm{MO} \times 10^{9} / \mathrm{L}$ & $0,7 \pm 0,04$ & $0,7 \pm 0,05$ & $0,5 \pm 0,08$ & $0,8 \pm 0,04$ & $0,6 \pm 0,03$ & up to 0,8 \\
\hline GRA $\times 10^{9} / \mathrm{L}$ & $0,6 \pm 0,03$ & $0,5 \pm 0,04$ & $0,4 \pm 0,02$ & $0,5 \pm 0,03$ & $0,5 \pm 0,03$ & $0,4-3,2$ \\
\hline LYM \% & $71,6 \pm 2,3$ & $67,7 \pm 2,8$ & $68,9 \pm 3,2$ & $73,1 \pm 3,6$ & $70,1 \pm 2,6$ & $63,7-90,1$ \\
\hline $\begin{array}{c}\text { MID \% } \\
(\mathrm{Mo}+\mathrm{Eo}+\mathrm{Ba})\end{array}$ & $15,5 \pm 1,2$ & $16,9 \pm 1,4$ & $14,2 \pm 1,6$ & $16,2 \pm 1,3$ & $17,4 \pm 1,6$ & $10-20$ \\
\hline GRA \% & $12,9 \pm 1,6$ & $15,4 \pm 1,8$ & $16,9 \pm 1,2$ & $10,7 \pm 1,4$ & $12,7 \pm 1,8$ & $7,3-30,1$ \\
\hline $\mathrm{RBC} \times 10^{12} / \mathrm{L}$ & $7,79 \pm 0,3$ & $7,45 \pm 0,3$ & $7,14 \pm 0,2$ & $7,77 \pm 0,26$ & $7,42 \pm 0,13$ & $5,6-7,89$ \\
\hline $\mathrm{Hgb} \mathrm{g} / \mathrm{L}$ & $144 \pm 7,8$ & $139 \pm 8,2$ & $147 \pm 5,4$ & $150 \pm 4,8$ & $138 \pm 5,8$ & $120-150$ \\
\hline НСТ \% & $40,4 \pm 1,8$ & $37,7 \pm 2,1$ & $42,2 \pm 1,6$ & $40,2 \pm 1,2$ & $42,2 \pm 2,2$ & $36-46$ \\
\hline MCV fl & $53,2 \pm 1,2$ & $54,6 \pm 0,9$ & $53,8 \pm 1,1$ & $53,8 \pm 1,4$ & $63,8 \pm 3,4$ & $53,0-68,8$ \\
\hline $\mathrm{MCH}$ pg & $19,5 \pm 1,3$ & $18,6 \pm 1,2$ & $19,2 \pm 1,2$ & $18,9 \pm 0,9$ & $17,6 \pm 1$ & $16,0-23,1$ \\
\hline $\mathrm{MCHC} \mathrm{g} / \mathrm{L}$ & $341 \pm 5,4$ & $338 \pm 5,8$ & $332 \pm 4,2$ & $323 \pm 3,8$ & $340 \pm 2,2$ & $300-341$ \\
\hline RDW \% & $14,7 \pm 1,1$ & $13,6 \pm 1,2$ & $12,6 \pm 1,4$ & $12,4 \pm 1,1$ & $11,4 \pm 2,1$ & $11,0-15,5$ \\
\hline PLT $10^{9} / \mathrm{L}$ & $736 \pm 159$ & $589 \pm 143$ & $430 \pm 136$ & $538 \pm 151$ & $632 \pm 161$ & $100-1610$ \\
\hline РCT \% & $0,256 \pm 0,06$ & $0,272 \pm 0,07$ & $0,258 \pm 0,1$ & $0,267 \pm 0,04$ & $0,233 \pm 0,06$ & $0,1-0,48$ \\
\hline MPV fl & $6,2 \pm 1,2$ & $6,2 \pm 1,6$ & $6,0 \pm \quad 1,0$ & $6,1 \pm 1,4$ & $6,0 \pm 0,4$ & $3,8-6,2$ \\
\hline PDW fl & $7,7 \pm 1,5$ & $9,2 \pm 1,6$ & $7,8 \pm 1,2$ & $8,3 \pm 1,1$ & $7,3 \pm 1,6$ & $7-23$ \\
\hline
\end{tabular}

The serum biochemical data collected after 14-day treatment by GAL, CU, $4 \mathbf{b}$ in two doses or placebo are given in Table 2. No abnormalities on the hepatic or renal functions were observed apart from transaminases (ALAT and ASAT) and uric acid. An increase in both transaminases by $\mathbf{4 b}$ was detected within the reference range. ALAT levels after treatment by the higher dose of $4 \mathrm{~b}$ are higher than the upper reference limit. The levels of uric acids were decresed by $\mathrm{CU}$ and $\mathbf{4 b}$ relatively to the control group but within the mice reference range.

Table 2. Serum biochemical data after 14-day treatment by GAL, CU, two doses of $\mathbf{4 b}$ or placebo. Values are means \pm standard deviation $(n=6)$. Mice reference ranges are given according to Ref. 30 and 31. In bold are given the increased or decreased values.

\begin{tabular}{|c|c|c|c|c|c|c|}
\hline $\begin{array}{l}\text { Serum Bio- } \\
\text { chemical Da- } \\
\text { ta }\end{array}$ & Control & GAL & $\mathrm{CU}$ & $\begin{array}{c}4 \mathrm{~b} \\
2.5 \mathrm{mg} / \mathrm{kg}\end{array}$ & $\begin{array}{c}4 \mathrm{~b} \\
5 \mathrm{mg} / \mathrm{kg}\end{array}$ & $\begin{array}{c}\text { Mice Ref- } \\
\text { erence } \\
\text { Range }\end{array}$ \\
\hline GLU mmol/L & $6,2 \pm 0,82$ & $6,1 \pm 0,77$ & $5,3 \pm 0,76$ & $6,1 \pm 0,84$ & $6,0 \pm 0,36$ & $4,2-7,5$ \\
\hline $\begin{array}{l}\text { UREA } \\
\mathrm{mmol} / \mathrm{L}\end{array}$ & $5,1 \pm 0,32$ & $4,0 \pm 0,36$ & $3,8 \pm 0,28$ & $4,5 \pm 0,22$ & $4,2 \pm 0,32$ & $3,27-12,1$ \\
\hline $\begin{array}{l}\text { CREAT } \\
\mu \mathrm{mol} / \mathrm{L}\end{array}$ & $68 \pm 2,3$ & $62 \pm 28,8$ & $65 \pm 6,6$ & $46 \pm 5,6$ & $56 \pm 4,6$ & $35-120$ \\
\hline $\mathrm{TP} g / \mathrm{L}$ & $58 \pm 2,2$ & $53 \pm 3,1$ & $54 \pm 2,6$ & $53 \pm 3,6$ & $54 \pm 2,6$ & $53-63$ \\
\hline ALB g/L & $27 \pm 1,8$ & $26 \pm 1,7$ & $26 \pm 2,2$ & $26 \pm 3,1$ & $27 \pm 2,3$ & $26-29$ \\
\hline ASAT U/L & $83 \pm 4,5$ & $96 \pm 5,2$ & $102 \pm 3,6^{*}$ & $123 \pm 4,1^{* *}$ & $123 \pm 5,3^{* *}$ & $65-122$ \\
\hline ALAT U/L & $58 \pm 2,2$ & $56,6 \pm 3,1$ & $62,2 \pm 3,3$ & $81,4 \pm 3,4^{* *}$ & $96 \pm 4,7^{* *}$ & $55-80$ \\
\hline
\end{tabular}




\begin{tabular}{|c|c|c|c|c|c|c|}
\hline T-Bil $\mu \mathrm{mol} / \mathrm{L}$ & $5,6 \pm 0,42$ & $6,0 \pm 0,38$ & $5,6 \pm 0,44$ & $6,3 \pm 0,28$ & $7,2 \pm 0,18$ & $3.9-9.6$ \\
\hline D-Bil $\mu \mathrm{mol} / \mathrm{L}$ & $2,4 \pm 0,32$ & $2,5 \pm 0,44$ & $2,4 \pm 0,46$ & $2,9 \pm 0,34$ & $3,6 \pm 0,24$ & $0-6.8$ \\
\hline $\mathrm{Ca} \mathrm{mmol} / \mathrm{L}$ & $2,04 \pm 0,11$ & $2,14 \pm 0,15$ & $2,04 \pm 0,21$ & $2,1 \pm 0,2$ & $2,2 \pm 0,1$ & $2.0-2.8$ \\
\hline $\begin{array}{l}\text { Uric acid } \\
\mu \mathrm{mol} / \mathrm{L}\end{array}$ & $195 \pm 18,4$ & $196 \pm 20,3$ & $133 \pm 23,7^{*}$ & $94 \pm 16,7^{*}$ & $104 \pm 26,7^{*}$ & $0-300$ \\
\hline $\begin{array}{l}\text { CHOL } \\
\mathrm{mmol} / \mathrm{L}\end{array}$ & $2,3 \pm 0,35$ & $2,61 \pm 0,28$ & $2,6 \pm 0,44$ & $2,16 \pm 0,36$ & $2,11 \pm 0,23$ & $1.77-2.9$ \\
\hline TRIG mmol/L & $1,04 \pm 0,12$ & $1,29 \pm 0,18$ & $1,02 \pm 0,2$ & $1,14 \pm 0,22$ & $1,04 \pm 0,32$ & $0.85-2.23$ \\
\hline ALP U/L & $148 \pm 12,9$ & $131 \pm 13,6$ & $122 \pm 14,9$ & $113 \pm 13,8^{*}$ & $123 \pm 11,6$ & $80-168$ \\
\hline GGT U/L & $13 \pm 2,1$ & $10 \pm 2,6$ & $10 \pm 1,8$ & $6 \pm 3,2^{*}$ & $8 \pm 4,4$ & $6-14$ \\
\hline AMYL U/L & $1021 \pm 86,2$ & $1179 \pm 74,6$ & $1036 \pm 64,3$ & $1263 \pm 66,7^{*}$ & $1068 \pm 53,4$ & $512-1312$ \\
\hline
\end{tabular}

\section{Discussion}

In the present study, we performed in vivo and ex vivo studies of a newly synthesized hybrid between GAL and CU aiming to combine the AChE inhibitory properties of GAL with the powerful antioxidant properties of $\mathrm{CU}$. Both properties have beneficial effect on the delay of neurodegeneration. As a result, an AChE inhibitor was generated, 186 times more potent than GAL in vitro ( $\mathrm{IC}_{50}$ of compound $\mathbf{4 b}=20 \mathrm{nM}$ vs. IC50 of GAL $=3.52 \mu \mathrm{M}$ ) [19].

The $\mathrm{LD}_{50}$ of $\mathbf{4 b}$ registered in the acute toxicity test on mice is $49 \mathrm{mg} / \mathrm{kg}$ orally. The $\mathrm{LD}_{50}$ of GAL in mice is $10 \mathrm{mg} / \mathrm{kg}$ i.p. [32] and between 15 and $45 \mathrm{mg} / \mathrm{kg}$ (median 30 $\mathrm{mg} / \mathrm{kg}$ ) orally [33]. The oral LD50 of CU is more than $2000 \mathrm{mg} / \mathrm{kg}$ (at highest given dose $2000 \mathrm{mg} / \mathrm{kg}$ ) [34,35]. Obviously, the presence of CU fragment in the molecule of $4 \mathbf{b}$ reduces its overall toxicity. The symptoms of toxic damage that were observed, expressed in breathing difficulty, initially rapid and then severely delayed, ataxia, lack of coordinated movements, tremor and tonic-clonic seizures, are characteristic of acetylcholine (ACh) neurotoxicity due to inhibition of AChE. In mammals, respiratory failure caused by inhibition of cerebral AChE is recognized as a cause of death [36]. In fish, the relationship between AChE inhibition and mortality is unclear, as some species are able to survive a high rate (90-95\%) of brain enzyme inhibition [37-39]. In this regard, some authors have found that $50 \%$ of AChE inhibition may indicate intoxication or poisoning [40]. No changes in the morphology of the internal organs (lungs, liver, heart, kidneys, stomach, spleen, intestines, gonads and brain) were observed.

The daily administration of $\mathbf{4 b}$ in doses of $2.5 \mathrm{mg} / \mathrm{kg}(1 / 20$ of LD50) and $5 \mathrm{mg} / \mathrm{kg}(1 / 10$ of LD50) for 14 days did not show any sign of toxicity in animals' behavior. The ex vivo AChE activity measured after this period showed that $4 \mathbf{b}$ inhibits the enzyme in a dose-dependent manner: $21 \%$ inhibition by the dose of $2.5 \mathrm{mg} / \mathrm{kg}$ and $25 \%$ - by the dose of $5 \mathrm{mg} / \mathrm{kg}$ compared to the control group (Figure 2). Such extent of AChE inhibition is not enough to cause toxic effects or mortality, but it leads to moderate increase in the levels of brain ACh. Any elevation of ACh levels in the brain are associated with improved cognitive effects [41], which was the purpose of the design of GAL-CU hybrids. The protective effect of GAL on mild to moderate Alzheimer's disease is due to its inhibitory effect on AChE, which was confirmed in the present study by the $16 \%$ reduction in AChE activity in mice brain homogenates. The neuroprotective and AChE inhibitory effects of curcumin and other curcuminoids is well known [42-44]. Our study also confirmed these effects: CU showed $12 \%$ reduction in the AChE activity in the tested brain 
homogenates. Being a congener of GAL and $\mathrm{CU}, \mathbf{4} \mathbf{b}$ accumulates and fortifies these effects and exerts more powerful AChE inhibition than both leads.

Tested in vitro $\mathbf{4 b}$ showed 186 times higher inhibitory effect on AChE than GAL [19]. In the present ex vivo studies, the difference in the reductions of AChE activity by $4 \mathbf{b}$ and GAL is only $5-9 \%$ in healthy animals. Some authors report reactivation of AChE, or even overproduction of an enzyme in response to inhibition [45]. The mild difference in the ex vivo AChE inhibition between $\mathbf{4 b}$ and GAL might be indicative for such recovery of AChE levels due to high spontaneous reactivation of the enzyme associated with rapid synthesis and release of a new enzyme from the liver. This possible mechanism requires further investigation.

The AChE inhibition in vivo is associated with increased oxidative stress [46,47]. In response, the increased oxidative stress mediates an increase in the AChE activity. The central nervous system is very sensitive to oxidative stress. The brain has many areas of high iron content, an activator of oxidative reactions, and neuronal mitochondria generate large amounts of hydrogen peroxide [9]. Neuronal membranes are rich in polyunsaturated fatty acids, which are also particularly susceptible to oxidative stress [9]. Due to the oxidative stress, the cholinergic neurons undergo a degeneration leading to impairments in cognition and memory. One of the strategies for prevention and treatment of Alzheimer's disease is focused on the suppression of oxidative damage $[7,8]$.

The association between AChE inhibition and increased oxidative stress also was observed in our MDA test. MDA is a biomarker of the oxidative stress relating to the lipid peroxidation. In the present study, we found that all tested AChE inhibitors elevated the MDA levels (Figure 3a). As stronger is the AChE inhibition, as bigger is the increase of MDA levels. In the same time, it was found in our GSH test that all tested compounds increased the GSH levels (Figure $3 b$ ). GSH is an important endogenous cellular protector and antioxidant. The increased GSH levels might be interpreted as a compensatory response of the brain to overcome the lipid peroxidation induced by the decreased AChE activity. Kaur и Sandhir [48] conducted acute and chronic toxicity studies in Wistar rats with two different oral doses of insecticide (AChE inhibitor). In this study, rats showed a decrease in GSH levels after acute pesticide exposure and an increase in GSH levels during chronic repeated administration. The authors suggest that GSH elevation is an adaptive response to increased oxidative stress.

GAL has an antioxidant activity related with the enolic $\mathrm{OH}$ group [6]. One of the mechanisms by which GAL improves the mental function in Alzheimer's dementia is thought to be its antioxidant effect [49-51]. CU also is a proven antioxidant and brain protector [52-54]. These effects were also confirmed in the present study, where CU and GAL significantly increased GSH levels by $52 \%$ and $35 \%$, respectively, compared to the control group. As a hybrid of GAL and $\mathrm{CU}, \mathbf{4 b}$ accrues and augments the antioxidant effects of its leads.

The analyses of the haematological and serum biochemical data point to some concern about the elevated values of ASAT and ALAT by $4 \mathbf{b}$. ASAT levels are slightly higher than the upper limit but ALAT levels rise by $20 \%$ above the upper limit of the mice reference range. $\mathrm{CU}$ and $\mathbf{4 b}$ decrease the serum levels of uric acid. CU inhibits xanthine oxidase and increases uricosuric activity $[55,56]$. As a CU congener, $4 \mathbf{b}$ might be also involved in the same mechanism.

Author Contributions: Conceptualization, R.S. and I.D.; methodology, R.S.; investigation, R.S., G.S., I.P., and M.A.; writing - original draft preparation, R.S.; writing - review and editing, R.S., G.S., I.P., M.A. and I.D.; supervision, I.D.; project administration, I.D.; funding acquisition, I.D. All authors have read and agreed to the published version of the manuscript.

Funding: This work was supported by the Bulgarian National Science Fund (Grant DN03/9/2016) and Grant No BG05M2OP001-1.001-0003, financed by the Science and Education for Smart Growth Operational Program (2014-2020) and co-financed by the European Union through the European Structural and Investment funds. 
Institutional Review Board Statement: The study was conducted according to the guidelines of the Declaration of Helsinki, and approved by the Animal Care Ethic Committee of the BULGARIAN AGENCY FOR FOOD SAFETY (protocol code 273 from 02/06/2020).

Informed Consent Statement: Not applicable

Data Availability Statement: Please refer to suggested Data Availability Statements in section "MDPI Research Data Policies" at https://www.mdpi.com/ethics.

Acknowledgments: Curcumin (Cursol $\left.{ }^{\circledR}\right)$ was kindly donated by BioXtract, Belgium.

Conflicts of Interest: The authors declare no conflict of interest. The funders had no role in the design of the study; in the collection, analyses, or interpretation of data; in the writing of the manuscript, or in the decision to publish the results.

\section{References}

1. Gammon K. Neurodegenerative disease: Brain windfall. Nature 2014, 515, 299-300

2. Cheung, J.; Rudolph, M. J.; Burshteyn, F.; Cassidy, M. S.; Gary, E. N.; Love, J.; Franklin, M. C.; Height, J. J. Structures of human acetylcholinesterase in complex with pharmacologically important ligands. J. Med. Chem. 2012, 55, 10282-10286.

3. Kita, Y.; Ago, Y.; Higashino, K.; Asada, K.; Takino, E.; Takuma, K.; Matsuda, T. Galantamine promotes adult hippocampal neurogenesis via M1 muscarinic and $\alpha 7$ nicotinic receptors in mice. Int. J. Neuropsychopharmacol. 2014, 17, $1957-1968$.

4. Dajas-Bailador, F. A.; Heimala, K.; Wonnacott, S. The allosteric potentiation of nicotinic acetylcholine receptors by galantamine is transduced into cellular responses in neurons: $\mathrm{Ca}^{2+}$ signals and neurotransmitter release. Mol. Pharmacol. 2003, 64, $1217-1226$.

5. Takata, K.; Kitamura, Y.; Saeki, M.; Terada, M.; Kagitani, S.; Kitamura, R.; Fujikawa, Y.; Maelicke, A.; Tomimoto, H.; Taniguchi, T.; Shimohama, S. Galantamine-induced amyloid- $\beta$ clearance mediated via stimulation of microglial nicotinic acetylcholine receptors. J. Biol. Chem. 2010, 285, 40180-40191.

6. Tsvetkova, D.; Obreshkova, D.; Zheleva-Dimitrova, D.; Saso, L. Antioxidant activity of galantamine and some of its derivatives. Curr. Med. Chem. 2013, 20, 4595-4608.

7. Markesbery, W. R. Oxidative stress hypothesis in Alzheimer's disease. Free Radic. Biol. Med. 1997, 23, $134-147$.

8. Butterfield, D.A. b-amyloid-associated free radical oxidative stress and neurotoxicity: implications for Alzheimer's disease. Chem. Res. Toxicol. 1997, 10, 495-506.

9. Cobley, J. N.; Fiorello, M. L; Bailey DM. 13 reasons why the brain is susceptible to oxidative stress. Redox Biol. 2018, 15, 490-503.

10. Perkins, A. J.; Hendrie, H. C.; Callahan, C. M.; Gao, S.; Unverzagt, F. W.; Xu, Y.; Hall, K. S.; Hui, S. L. Association of antioxidants with memory in a multiethnic elderly sample using the Third National Health and Nutrition Examination Survey. Am. J. Epidemiol. 1999, 150, 37-44.

11. Masaki, K. H.; Losonczy, K. G.; Izmirlian, G.; Foley, D. J.; Ross, G. W.; Petrovitch, H.; Havlik, R.; White, L. R. Association of vitamin $\mathrm{E}$ and $\mathrm{C}$ supplement use with cognitive function and dementia in elderly men. Neurology 2000, 54, $1265-1272$.

12. Morris, M. C.; Evans, D. A.; Bienias, J. L.; Tangney, C. C.; Bennett, D. A.; Aggarwal, N.; Wilson, R. S.; Scherr, P. A. Dietary intake of antioxidant nutrients and the risk of incident Alzheimer disease in a biracial community study. JAMA 2002, 287, 3230-3237.

13. Grodstein, F.; Chen, J.; Willett, W. C. High-dose antioxidant supplements and cognitive function in community-dwelling elderly women. Am. J. Clin. Nutr. 2003, 77, 975-984.

14. Engelhart, M. J.; Geerlings, M. I.; Ruitenberg, A.; van Swieten, J. C.; Hofman, A.; Witteman, J. C.; Breteler, M. M. Dietary intake of antioxidants and risk of Alzheimer disease. JAMA 2002, 287, 3223-3229.

15. Sano, M.; Ernesto, C.; Thomas, R. G.; Klauber, M. R.; Schafer, K.; Grundman, M.; Woodbury, P.; Growdon, J.; Cotman, C. W.; Pfeiffer, E.; Schneider, L. S.; Thal, L. J. A controlled trial of seligiline, a-tocopherol, or both as treatment for Alzheimer's disease. N. Engl. J. Med. 1997, 336, 1216-1222.

16. Menon, V. P.; Sudheer, A. R. Antioxidant and anti-inflammatory properties of curcumin. Adv. Exp. Med. Biol. 2007, 595, 105-125.

17. Lim, G. P.; Chu, T.; Yang, F.; Beech, W.; Frautschy, S. A.; Cole, G. M. The curry spice curcumin reduces oxidative damage and amyloid pathology in an Alzheimer' transgenic mouse. J. Neurosci. 2001, 21, 8370-8377.

18. Zhao, L.N.; Chiu, S.W.; Benoit, J.; Chew, L.Y.; Mu, Y. The effect of curcumin on the stability of A $\beta$ dimers. J. Phys. Chem. B 2012, 116, 7428-7435.

19. Stavrakov, G.; Philipova, I.; Lukarski, A.; Atanasova, M.; Zheleva, D.; Zhivkova, Z. D.; Ivanov, S.; Atanasova, T.; Konstantinov, S.; Doytchinova, I. Galantamine-curcumin hybrids as dual-site binding acetylcholinesterase inhibitors. Molecules 2020, $25,3341$.

20. Masuda, Y.; Fukuchi, M.; Yatagawa, T.; Tada, M.; Takeda, K.; Irie, K.; Akagi, K.; Monobe, Y.; Imazawa, T.; Takegoshi, K. Solid-state NMR analysis of interaction sites of curcumin and 42-residue amyloid beta-protein fibrils. Bioorg. Med. Chem. 2011, 19, 5967-5974. 
21. Jia, P.; Sheng, R.; Zhang, J.; Fang, L.; He, Q.; Yang, B.; Hu, Y. Design, synthesis and evaluation of galanthamine derivatives as acetylcholinesterase inhibitors. Eur. J. Med. Chem. 2009, 44, 772-784.

22. OECD Test No. 425. Acute Oral Toxicity: Up-and-Down Procedure, OECD Guidelines for the Testing of Chemicals, Section 4, OECD Publishing, Paris, 2008.

23. Lorke D. A new approach to practical acute toxicity testing. Arch. Toxicol. 1983, 54, 275-287.

24. Sadigh-Eteghad, S.; Mahmoudi, J.; Babri, S.; Talebi, M. Effect of alpha-7 nicotinic acetylcholine receptor activation on beta-amyloid induced recognition memory impairment. Possible role of neurovascular function. Acta Cir. Bras. 2015, 30, 736-742.

25. Akinyemi, A. J.; Oboh, G.; Fadaka, A. O.; Olatunji, B. P.; Akomolafe, S. Curcumin administration suppress acetylcholinesterase gene expression in cadmium treated rats. Neurotoxicology 2017, 62, 75-79.

26. Lowry, O. H.; Rosebrough, N. J.; Farr, A. L.; Randall, R. J. (1951) Protein measurement with the Folin phenol reagent. J. Biol. Chem. 1951, 193, 265-275.

27. Ellman, G. L.; Courtney, K. D.; Andre, J. V.; Featherstone, R. M. A new and rapid colorimetric determination of acetylcholinesterase activity. Biochem. Pharmacol. 1961, 7, 88-95.

28. Deby, C.; Goutier, R. (1990) New perspectives on the biochemistry of superoxide anion and the efficiency of superoxide dismutases. Biochem. Pharmacol. 1990, 39, 399-405.

29. Bump, E. A.; Taylor, Y. C.; Brown, J. M. Role of glutathione in the hypoxic cell cytotoxicity of misonidazole. Cancer Res. 1983, 43, 997-1002.

30. Stahl, F. R.; Jung, R.; Jazbutyte, V.; Ostermann, E.; Tödter, S.; Brixel, R.; Kemmer, A; Halle, S.; Rose-John, S.; Messerle, M.; Arck, P. C.; Brune, W.; Renné, T. (2018). Laboratory diagnostics of murine blood for detection of mouse cytomegalovirus (MCMV)-induced hepatitis. Sci. Rep. 2018, 8, 14823.

31. Otto, G. P.; Rathkolb, B.; Oestereicher, M. A.; Lengger, C. J.; Moerth, C.; Micklich, K.; Fuchs, H.; Gailus-Durner, V.; Wolf, E.; Hrabě de Angelis, M. (2016). Clinical chemistry reference intervals for C57BL/6J, C57BL/6N, and C3HeB/FeJ mice (Mus musculus). J. Am. Assoc. Lab Anim. Sci. 2016, 55, 375-386.

32. Cayman Chemicals. Galantamine. Safety data sheet. https://caymanchem.com/ msdss/17559m.pdf

33. Auro-Galantamine. Product monograph. AuroPharma Inc., Canada, 2017

34. ChemlDpus datadase, US National Library of Medicine

35. Srimal, R. C.; Dhawan, B. N. Pharmacology of diferuloyl methane (curcumin), a non-steroidal anti-inflammatory agent. J. Pharm. Pharmacol. 1973, 25, 447-452.

36. Chambers, H. W.; Boone, J. S.; Carr, R. L.; Chanbers, J. E. Chemistry of organophosphorus insecticides. In: Robert IK, editor. Handbook of Pesticide Toxicology. 2nd ed.; Academic Press: California, USA, 2001; pp. 913-917.

37. Ferrari, A.; Anguiano, O. L.; Soleño, J.; Venturino, A.; Pechen de D'Angelo, A. M. Different susceptibility of two aquatic vertebrates (Oncorhynchus mykiss and Bufo arenarum) to azinphos methyl and carbaryl. Comp. Biochem. Physiol. 2004, 139C, 239-243.

38. Ferrari, A.; Venturino, A.; de D'Angelo, A. M. The time course of brain cholinesterase inhibition and recovery following acute and subacute azinphosmethyl, parathion and carbaryl exposure in the goldfish (Carassius auratus). Ecotoxicol. Environ. Saf. 2004, 57, 420-425.

39. Ferrari, A.; Venturino, A.; Pechén de D'Angelo, A. M. Muscular and brain cholinesterase sensitivities to azinphos methyl and carbaryl in the juvenile rainbow trout Oncorhynchus mykiss. Comp. Biochem. Physiol. C Toxicol. Pharmacol. 2007, 146, 308-313.

40. Dembélè, K.; Haubruge, E.; Gaspar, C. Concentration effects of selected insecticides on brain acetylcholinesterase in the common carp (Cyprinus carpio L.). Ecotoxicol. Environ. Saf. 2000, 45, 49-54.

41. Tata, A. M.; Velluto, L.; D'Angelo, C.; Reale, M. Cholinergic system dysfunction and neurodegenerative diseases: Cause or effect? CNS Neurol. Disord. Drug Targets 2014, 13, 1294-1303.

42. Akinyemi, A. J.; Oboh, G.; Fadaka, A. O.; Olatunji, B. P.; Akomolafe, S. Curcumin administration suppress acetylcholinesterase gene expression in cadmium treated rats. Neurotoxicology 2017, 62, 75-79.

43. Manap, A. S. A.; Tan, A. C. W.; Leong, W. H.; Chia, A. Y. Y.; Vijayabalan, S.; Arya, A.; Wong, E. H.; Rizwan, F.; Bindal, U.; Koshy, S.; Madhavan P. Synergistic effects of curcumin and piperine as potent acetylcholine and amyloidogenic inhibitors with significant neuroprotective activity in SH-SY5Y cells via computational molecular modeling and in vitro assay. Front. Aging Neurosci. 2019, 11, 206.

44. Dhir, A. Curcumin in Neurological Disorders: An Overview. In Curcumin for Neurological and Psychiatric Disorders, Farooqui, T., Farooqui, A. A., Eds.; Academic Press, USA, 2019; pp. 63-84.

45. Blaber, L. C.; Creasey, N. H. The mode of recovery of cholinesterase activity in vivo after organophosphorus poisoning. Biochem. J. 1960, 77, 597-604.

46. Milatovic, D.; Gupta, R. C.; Aschner, M. Anticholinesterase toxicity and oxidative stress. TheScientificWorld Journal, 2006, 6, 295310 . 
47. Hernández-Moreno, D.; Soler, F.; Míguez, M. P.; Pérez-López, M. Brain acetylcholinesterase, malondialdehyde and reduced glutathione as biomarkers of continuous exposure of tench, Tinca tinca, to carbofuran or deltamethrin. Sci. Total Environ. 2010, 408, 4976-4983.

48. Kaur, M.; Sandhir, R. Comparative effects of acute and chronic carbofuran exposure on oxidative stress and drug-metabolizing enzymes in liver. Drug Chem. Toxicol. 2008, 29, 415-421.

49. Naguib, S., Bernardo-Colón, A., Cencer, C., Gandra, N., Rex, T. S. Galantamine protects against synaptic, axonal, and vision deficits in experimental neurotrauma. Neurobiol. Dis. 2020, 134, 104695.

50. Koola, M.M., Praharaj, S.K. Pillai, A. Galantamine-memantine combination as an antioxidant treatment for schizophrenia. Curr. Behav. Neurosci. Rep. 2019, 6, 37-50.

51. Castillo, W. O.; Aristizabal-Pachon, A. F. Galantamine protects against beta amyloid peptide-induced DNA damage in a model for Alzheimer's disease. Neural Regen. Res. 2017, 12, 916-917.

52. Cole, G. M.; Teter, B.; Frautschy, S. A. Neuroprotective effects of curcumin. Adv. Exp. Med. Biol. 2007, 595, $197-212$.

53. Abrahams, S.; Haylett, W. L.; Johnson, G.; Carr, J. A.; Bardien, S. Antioxidant effects of curcumin in models of neurodegeneration, aging, oxidative and nitrosative stress: A review. Neuroscience 2019, 406, 1-21.

54. Nery-Flores, S. D.; Mendoza-Magaña, M. L.; Ramírez-Herrera, M. A.; Ramírez-Vázquez, J. J.; Romero-Prado, M.; Cortez-Álvarez, C. R.; Ramírez-Mendoza, A. A. Curcumin exerted neuroprotection against ozone-induced oxidative damage and decreased NF- $\kappa B$ activation in rat hippocampus and serum levels of inflammatory cytokines. Oxid. Med. Cell Longev. 2018, 2018, 9620684.

55. Bupparenoo, P.; Pakchotanon, R.; Narongroeknawin, P.; Asavatanabodee, P.; Chaiamnuay, S. Effect of curcumin on serum urate in asymptomatic hyperuricemia: A randomized placebo-controlled trial. J. Diet. Suppl. 2020, 1-13.

56. Panahi, Y., Kianpour, P., Mohtashami, R., Jafari, R., Simental-Mendía, L. E., Sahebkar, A. Curcumin lowers serum lipids and uric acid in subjects with nonalcoholic fatty liver disease: A randomized controlled trial. J. Cardiovasc. Pharmacol. 2016, 68, 223-229. 